\title{
DESIGN OF YARN PROPERTIES FOR IMPROVED FABRIC PERFORMANCE
}

\section{SALOPEK C., I. \& SKENDERI, Z.}

Abstract: Textile fabrics cover a vast range of consumer and industrial products made from natural and. In the production process, fibers have to be spun into a carefully designed yarn structure with specified properties, in order to give the desired aesthetics and/or technical performance. This chapter covers the investigation of different yarn properties - evenness, tensile properties, hairiness and friction considering the differences in fibre type and yarn count. The values of each measured property are discussed and finally, the quality of yarns for the knitting process is evaluated.

Key words: yarn, textile, evenness, tensile, hairiness
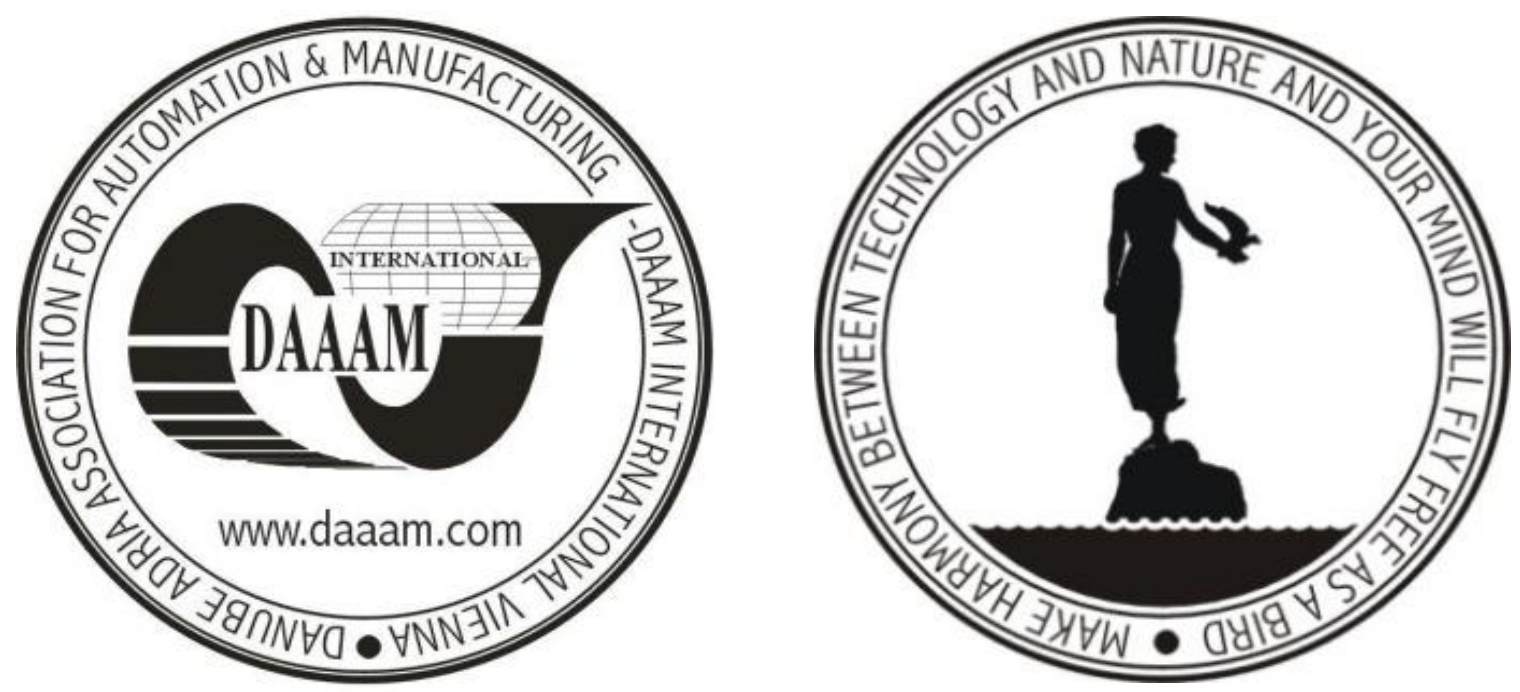

Authors' data: Assist. Prof. Dr. Sc. Salopek Cubric, I[vana]; Prof. Dr. Sc. Skenderi, Z[enun], University of Zagreb, Faculty of Textile Technology, Prilaz baruna Filipovica 28a, 10000 Zagreb, Croatia, ivana.salopek@ttf.hr, zenun.skenderi@ttf.hr

This Publication has to be referred as: Salopek Cubric, I[vana] \& Skenderi, Z[enun] (2014). Design of Yarn Properties for Improved Fabric Performance, Chapter 04 in DAAAM International Scientific Book 2014, pp.051-062, B. Katalinic (Ed.), Published by DAAAM International, ISBN 978-3-901509-98-8, ISSN 17269687, Vienna, Austria

DOI:10.2507/daaam.scibook.2014.04 


\section{Introduction}

Textile fabrics cover a vast range of consumer and industrial products made of natural and man-made fibers. In the production process, fibers have to be spun into a carefully designed yarn structure, in order to give the desired aesthetics and/or technical performance (Lawrence, 2003). In the manufacture of knitted fabrics, there are certain minimum requirements for the yarn that interacts with other parameters during production. Yarns have restricted value in themselves because their value lies in the contribution to the structure and properties of textile products. Among a number of fabric properties that are affected by yarn properties, significant influence is reported for the transfer of heat and water vapor (Salopek Cubric et al. 2013; Salopek Cubric \& Skenderi, 2007 \& 2010).

Recently, there was a number of studies related to the properties of ring spun yarns, but majority of the studies focused either at the yarns produced from the same raw material, or at the investigation of limited number of yarn properties. In the study carried out by Ünal et al., the effects of parameters on tenacity and elongation of yarns are investigated. As a result of the study, equations and neural network models that predict the tenacity and elongation of yarns are obtained. According to the authors, the obtained equations and models are statistically important and have high coefficient of multiple determination (Ünal et al., 2009). Fibre length is one of the key properties of cotton and has important influence on yarn production and yarn quality. The study carried by Cai et al. is focused at the investigation of fibre length and its influence on two yarn properties - strength and irregularity (Cai et al., 2013). On the basis of investigation, linear regression models are developed to predict spun yarns' properties. In another study, the intention was to predict the most important yarn quality characteristic derived from cotton fibre properties measured by means of a High Volume Instrument (HVI), (Ureyen \& Kadikoglu, 2006). Linear multiple regression methods were used for the estimation of yarn quality characteristics. In the article written by Dayik (Dayik, 2009) are proposed approaches for the determination of the breaking strength of the yarn. The results obtained from the computational tests show that developed "GEP" (Gene expression programing) technique is a good technique in terms of precision and prediction of yarn properties $(98.88 \%)$.

Taking into account that a number of published studies focused at only one raw material or certain yarn property, the intention of the study presented in this chapter is to get a comprehensive overview. Therefore, for the investigation are carefully designed 18 yarns that differ considering the raw material and count. In the study are observed and discussed changes in tensile properties, evenness, hairiness and friction among designed yarns.

\section{Experiment}

\subsection{Yarn raw materials}

For the purposes of this study the following raw materials are selected: $100 \%$ cotton, 50/50\% cotton/modal, $100 \%$ viscose, $100 \%$ lyocel $\left(\right.$ Tencel ${ }^{\circledR}$ ) and $100 \%$ polyester standard and $100 \%$ polyester with profiled cross-section. From the named 
raw materials, combed single yarns were produced. The yarns are made in four counts: 20, 17, 14 and 12 tex for each raw material type. The average twist coefficient of produced yarns $\left(\alpha_{\text {tex }}\right)$ is 3417 (Salopek Cubric, 2009). The list of produced yarns with designation and basic determinants is shown in the Tab. 1.

\begin{tabular}{|c|c|c|c|}
\hline Nr. & Designation & Raw material & Yarn count, tex \\
\hline 1 & C1 & Cotton & 20 \\
\hline 2 & C2 & Cotton & 17 \\
\hline 3 & C3 & Cotton & 14 \\
\hline 4 & C4 & Cotton & 20 \\
\hline 5 & CM1 & Cotton + modal & 17 \\
\hline 6 & CM2 & Cotton + modal & 14 \\
\hline 7 & CM3 & Cotton + modal & 12 \\
\hline 8 & CM4 & Cotton + modal & 20 \\
\hline 9 & V1 & Viscose & 17 \\
\hline 10 & V2 & Viscose & 14 \\
\hline 11 & V3 & Viscose & 20 \\
\hline 12 & V4 & Viscose & 17 \\
\hline 13 & T1 & Tencel & 14 \\
\hline 14 & T2 & Tencel & \\
\hline 15 & T3 & Tencel & 12 \\
\hline 16 & T4 & Tencel & \\
\hline 17 & PE1 & Polyester standard & 20 \\
\hline 18 & PE2 & Polyester profiled & 20 \\
\hline
\end{tabular}

Tab. 1. Yarn designation and basic determinants

\subsection{Measurement}

Within the scope of the experimental part, the following yarn properties were tested: evenness, tensile properties, hairiness and coefficient of yarn friction (against metallic surface). All tested yarns are taken from the cones.

The parameters that characterize the evenness of yarn i.e. number of faults per $1 \mathrm{~km}$ i.e. thin places (Ntn), thick places (Ntk), neps (Ntn) mass variation expressed by coefficient of variation $(\mathrm{CVm}$, cut length of $1 \mathrm{~cm})$ are measured using the Keisokki evenness tester, model KET-80. During the measurement, the following sensibility levels are used: $-50 \%$ for thin places, $+50 \%$ for thick places and $+200 \%$ for neps. Tensile properties of produced yarns, i.e. breaking force $(F)$, breaking elongation $\left(\varepsilon_{B}\right)$, work to rupture $(\mathrm{Wr})$ and tenacity $(\mathrm{T})$ are measured on a dynamometer Statimat $\mathrm{M}$ produced by Textechno, as described in ISO standard (ISO 2062, 2009). The number of fibers in different lengths $(2,4,6$ and $8 \mathrm{~mm})$ is determined using the hairiness meter produced by Zweigle company. The speed of yarn delivery is set to $50 \mathrm{~m} \times \mathrm{min}^{-}$ ${ }^{1}$. Finally, the coefficient of yarn friction $(\mu)$ was determined using the F-meter G 534 produced by Zweigle, according to the ASTM standard (ASTM D 3108-07, 2007). 


\section{Results and discussion}

The results of yarn evenness measurement are shown on Figures 1-3. Number of thin places on all investigated yarns is zero, and therefore the graphical presentation of this indicator is omitted. As seen from the Fig. 1., number of thick places for all investigated yarns is $0-60$ and on average increases with the reduction of yarn count - with increasing the yarn fineness, except for viscose yarn of 20 count. The reason of that may be the mechanical damage of someone elements of production machinery (spinning machine, roving frame or drawing machine). The number of neps is 0-118 and on average is generally higher for finer yarns. For yarns that are used in the knitting process, it is of great importance to have lower number of yarn faults i.e. thick places and neps because they may cause the breakage of threads, higher wear of needles, appearance of uneven fabric surface and low color egality. As seen from the Fig. 3., coefficients of mass variation are in the range 5 to $14 \%$ and are highest for yarns in count of 12 tex.

Considering the influence of raw material to the evenness parameters, the results indicated that the highest number of thick places is present on yarns produced of natural fibers. Unlike staten, there are no regularities for the influence of raw material on the number of neps and coefficient of mass variation. The results also indicated significant differences between the two yarns produced of polyester. Namely, it was shown that polyester with profiled cross-section has higher values of all measured parameters that characterize the yarn evenness.

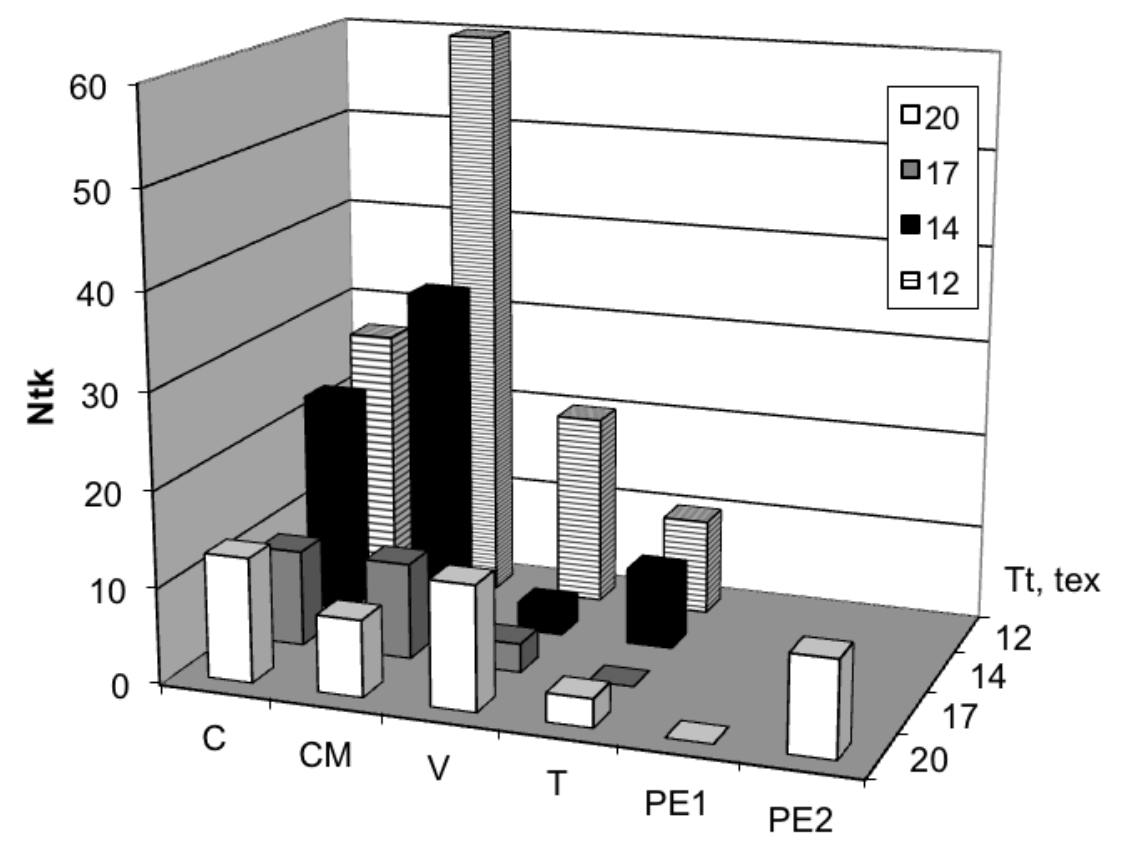

Fig. 1. Number of thick places 


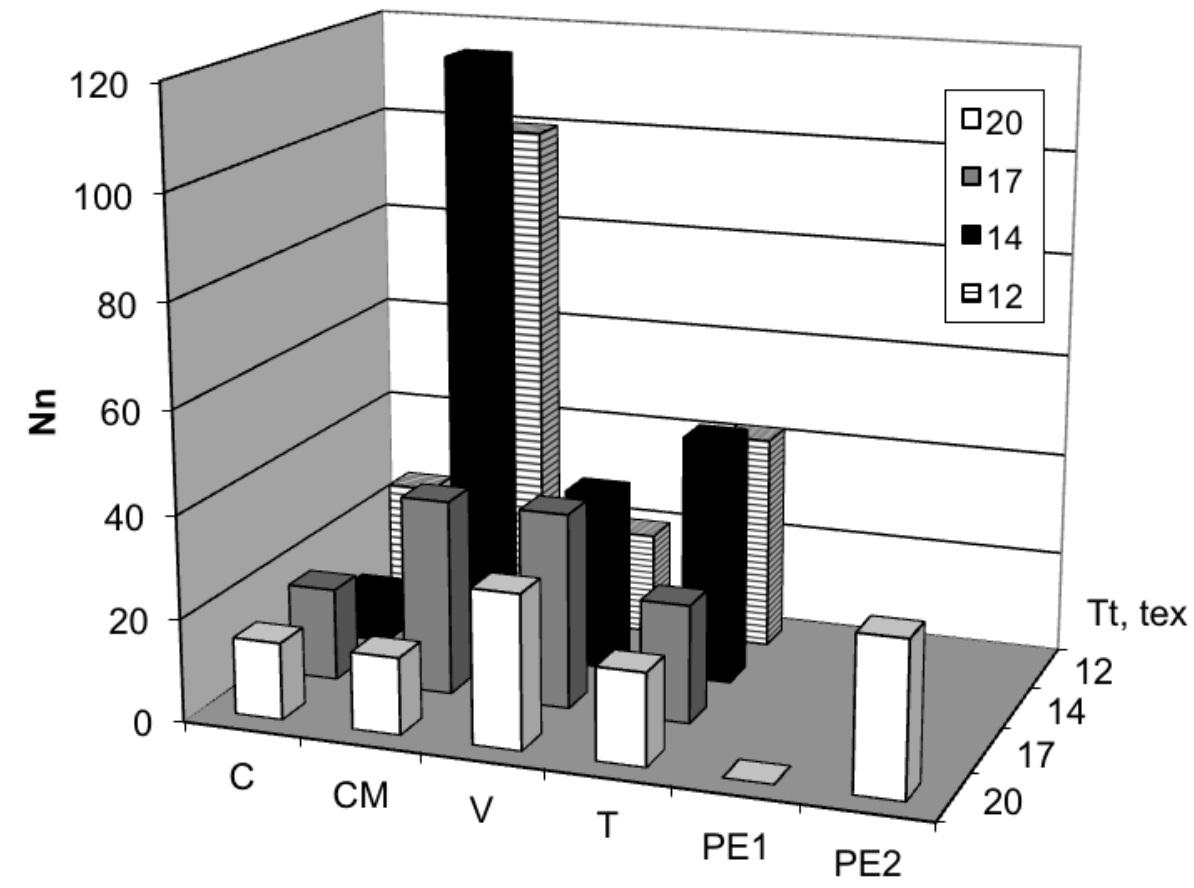

Fig. 2. Number of neps

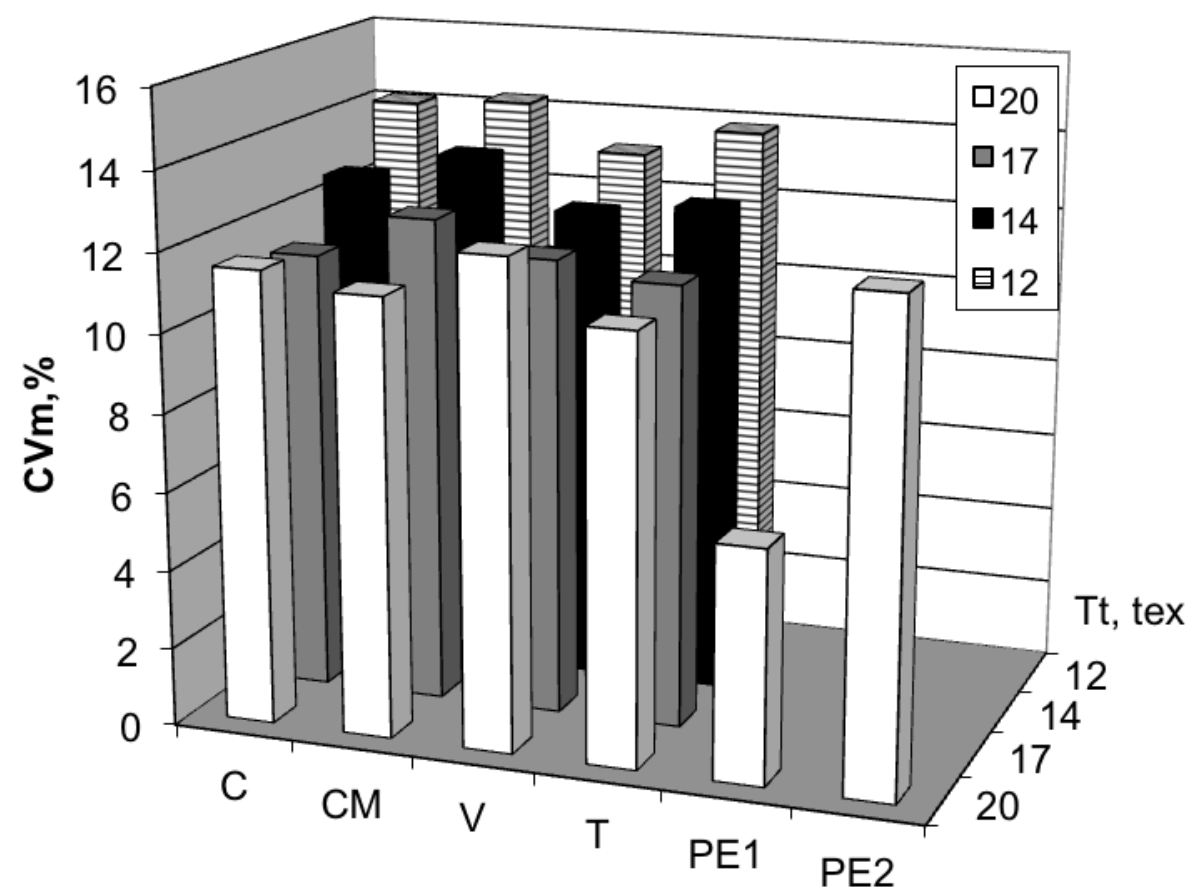

Fig. 3. Coefficient of mass variation 
The test results of yarn evenness are also compared with with Uster ${ }^{\circledR}$ statistics (Uster $^{\circledR}$ Statistics, 2007). Generally, Uster ${ }^{\circledR}$ Statistics is used primarily for comparison as well as classification of fibers, slivers, rovings and yarns in relation to world production. Comparison of thin places, thick places, neps and coefficients of mass variation with the results provided by $\mathrm{Uster}^{\circledR}$ is shown in the Tab. 2. From the comparison, it can be seen that for a number of cases, the values are below the line of $5 \%$. That particularly applies to yarns made of viscose and Tencel ${ }^{\circledR}$. With regard to the comparison of evenness parameters with recommended values from the literature, it may be concluded that the overall assessment of the quality of yarn intended for knitting is very high.

\begin{tabular}{|c|c|c|c|c|}
\hline \multirow{2}{*}{ Sample } & \multicolumn{5}{|c|}{$\begin{array}{c}\text { Percentage of producers that produce yarn with same or higher values of } \\
\text { a single evenness parameter }\end{array}$} \\
\cline { 2 - 5 } & $\begin{array}{c}\text { Number of thin } \\
\text { places }\end{array}$ & $\begin{array}{c}\text { Number of thick } \\
\text { places }\end{array}$ & Number of neps & $\begin{array}{c}\text { Coefficient of } \\
\text { mass variation }\end{array}$ \\
\hline C1 & 50 & 5 & $<5$ & 25 \\
\hline C2 & 50 & $<5$ & $<5$ & 5 \\
\hline C3 & 25 & 25 & $<5$ & $5-25$ \\
C4 & 5 & 25 & $<5$ & 75 \\
\hline CM1 & 50 & $<5$ & 5 & 25 \\
\hline CM2 & 50 & 5 & $5-25$ & $5-25$ \\
\hline CM3 & 25 & 50 & 50 & 25 \\
CM4 & 5 & 75 & 75 & 75 \\
\hline V1 & $<5$ & 25 & 5 & 50 \\
\hline V2 & $<5$ & $<5$ & 5 & 5 \\
\hline V3 & $<5$ & $<5$ & 5 & 5 \\
V4 & $<5$ & 5 & $<5$ & $<5$ \\
\hline T1 & $<5$ & $<5$ & $<5$ & 5 \\
\hline T2 & $<5$ & $<5$ & 5 & 25 \\
\hline T3 & $<5$ & $<5$ & 5 & 50 \\
\hline T4 & $<5$ & $<5$ & 5 & 5 \\
\hline PE1 & $<5$ & $<5$ & $<5$ & \\
\hline PE2 & $<5$ & 25 & 50 & $<5$ \\
\hline
\end{tabular}

Tab. 2. Comparison of evenness parameters with Uster ${ }^{\circledR}$ Statistics

From the values of yarn breaking force that are obtained by testing samples on the dynamometer, an increase in breaking force with the increasing the yarn fineness is seen. The lowest values of breaking force are measured for yarns in count of 12 tex and amount 158-296 N. The highest value of $713 \mathrm{cN}$ is recorded for the coarsest yarn (count is 20 tex). A comparison of breaking forces for the samples of different 
counts, but the same composition, reveals that the largest differences are between the samples made of Tencel ${ }^{\circledR}$ fibers. Within the mentioned group of samples, breaking force of coursest yarn (sample T1) is even $241 \%$ higher than the breaking force of finest yarn (sample T4). The smallest difference between breaking forces among the samples of the same raw material, but different count is measured for cotton samples. Influence of fiber cross-sectional shape is not significant for breaking force of yarn, what can be seen by comparing samples made of polyester (PE1 and PE2).

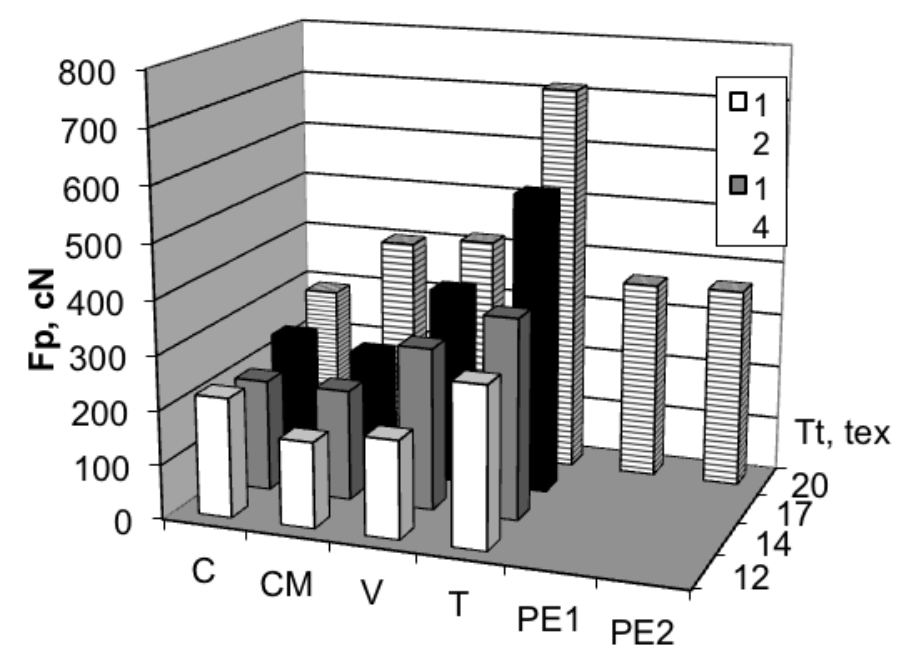

Fig. 4. Breaking force of investigated yarns

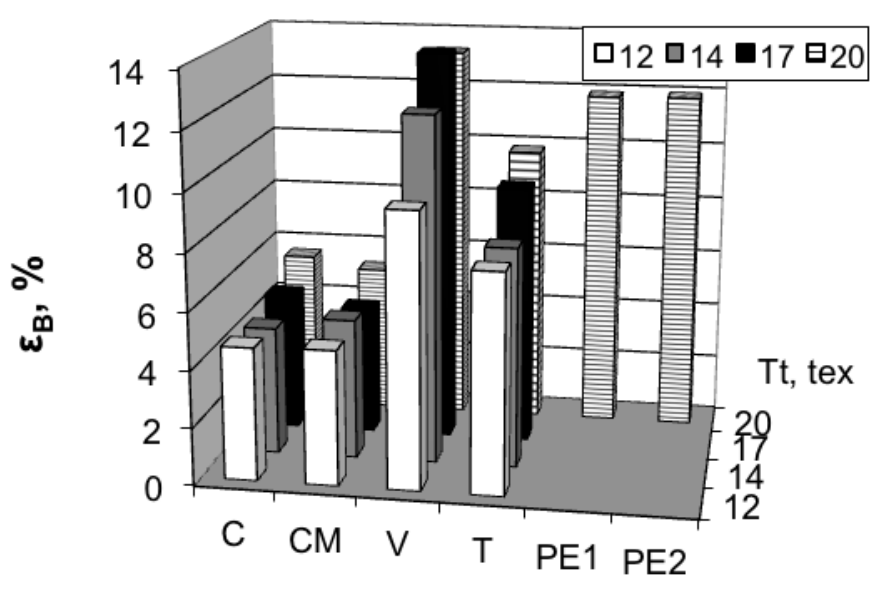

Fig. 5. Breaking elongation of investigated yarns

Breaking elongation of tested samples ranges from 4 to $13 \%$, with coefficients of variation from 5 to $12 \%$. Due to the nature of the process, yarn for knitting must be sufficiently flexible and stretchable. According to the literature data, the optimal elongation of yarns for knitting is up to $8 \%$ for cotton yarns and $9-17 \%$ for viscose yarns (Iyer et al., 1992). As the elongation of investigated cotton yarns is from 4 to 
Salopek Cubric, I. \& Skenderi, Z.: Design of Yarn Properties for Improved Fabric ...

$5 \%$ and 9 to $13 \%$ for viscose yarns, it is to conclude that the values are within the specified range. Yarns made of regenerated cellulose fibers (samples V1-V4 and T1T4) and a synthetic polymer (samples PE1 and PE2) have higher elongation than yarns made of other observed fibers. It is also observed that, on average, elongation decreases with increase of yarn fineness. It is obtained that work done to rupture is from 180 to $2000 \mathrm{cN} \times \mathrm{cm}$. The highest values obtained to yarns spun from Tencel, viscose and PET fibers (Fig. 6). The yarns spun from cottton fibers as well as blend cotton/Modal have relatively lowest work.

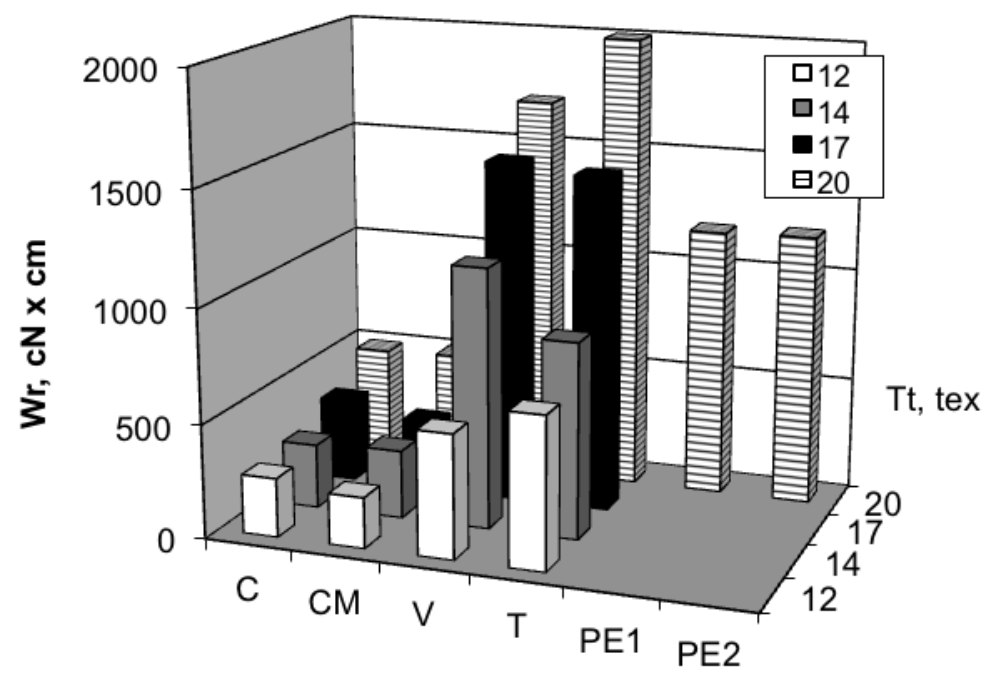

Fig. 6. Work to rupture of investigated yarns

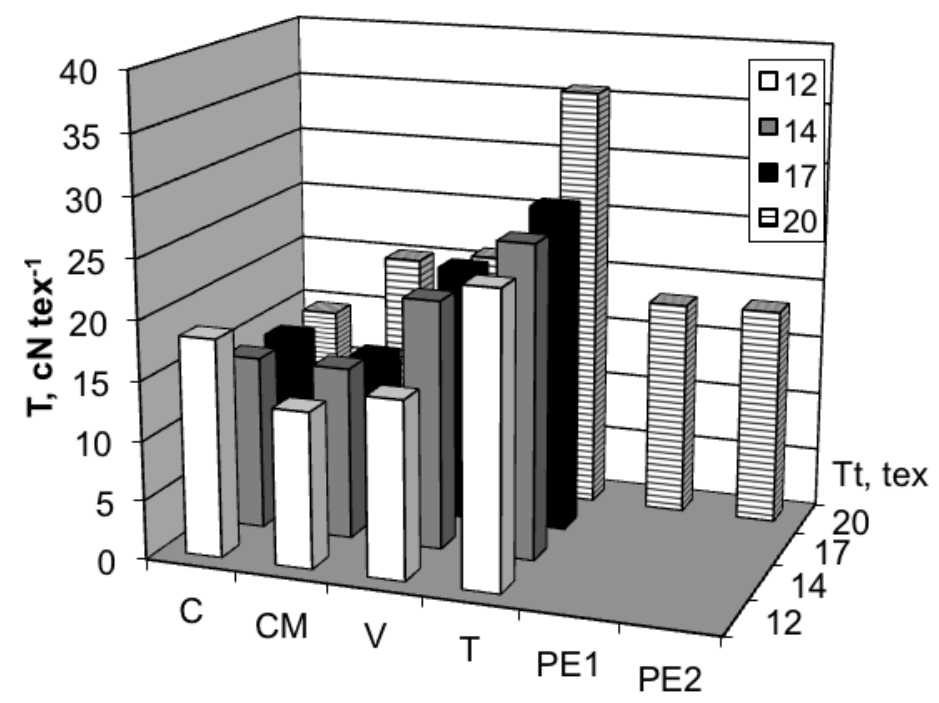

Fig. 7. Tenacity of investigated yarns 
Tenacity of knitting yarns is, unlike the tenacity of weaving yarns, of minor importance because the load of yarn during the knitting process is lower than a load during weaving. However, the tenacity of yarns for knitting must be sufficient to handle loads on knitting machine and to contribute the required stability of fabric. Requirements for the minimal tenacity of yarn is not clearly defined in the literature. According to some authors, the optimal tenacity of cotton combed yarn for knitting is 10-22 $\mathrm{cN} \times t e x^{-1}$ (Iyer et al., 1992). From the comparison of values obtained for investigated cotton yarns with values from the literature, it is concluded that the strength of the yarn produced is optimal for knitting (values are in the range 14 to 18 $\mathrm{cN} \times \mathrm{tex}^{-1}$ ).

Comparison of tensile properties with Uster ${ }^{\circledR}$ statistics is shown in Tab. 3. From the comparison, the wider range of values can be seen.

\begin{tabular}{|c|c|c|c|c|}
\hline \multirow{2}{*}{ Sample } & \multicolumn{4}{|c|}{ Percentage of producers that produce yarn with same or higher values } \\
\cline { 2 - 5 } & Breaking force & $\begin{array}{c}\text { Breaking } \\
\text { elongation }\end{array}$ & Work to rupture & Tenacity \\
\hline C1 & 95 & 75 & 50 & $<95$ \\
\hline C2 & 95 & 75 & $50-95$ & $<95$ \\
\hline C3 & 95 & 95 & 95 & $<95$ \\
C4 & 75 & 75 & 95 & 75 \\
\hline CM1 & 5 & 50 & 50 & 5 \\
\hline CM2 & $<95$ & 95 & 95 & $<95$ \\
\hline CM3 & 95 & 50 & $50-95$ & $<95$ \\
CM4 & $<95$ & 75 & $<95$ & $<95$ \\
\hline V1 & 50 & 50 & $5-50$ & 5 \\
\hline V2 & 50 & $5-50$ & 5 & 5 \\
\hline V3 & 50 & 50 & 50 & 5 \\
V4 & 95 & $<95$ & $<95$ & $50-95$ \\
\hline T1 & 5 & $<95$ & 5 & 5 \\
\hline T2 & 5 & $<95$ & $5-50$ & 5 \\
\hline T3 & 5 & $<95$ & $50-95$ & 5 \\
T4 & 5 & $<95$ & 95 & 5 \\
\hline PE1 & $<95$ & 50 & $<95$ & $<95$ \\
\hline PE2 & $<95$ & 50 & $<95$ & $<95$ \\
\hline
\end{tabular}

Tab. 3. Comparison of tensile parameters with Uster ${ }^{\circledR}$ Statistics

The results of yarn hairiness measurement are graphically expressed through the number of protruding fibers in the lengths 2 and $4 \mathrm{~mm}$ per 1 meter (Fig. 8 and 9). As seen from the figures, investigated yarns have $26-60$ protruding fibers in the length of $2 \mathrm{~mm}$ and 3-22 fibers in the length of $4 \mathrm{~mm}$. The number of increases with the 
Salopek Cubric, I. \& Skenderi, Z.: Design of Yarn Properties for Improved Fabric ... reduction of yarn fineness. Significant differences in the number of protruding fibers are observed between samples made of polyester fibers.

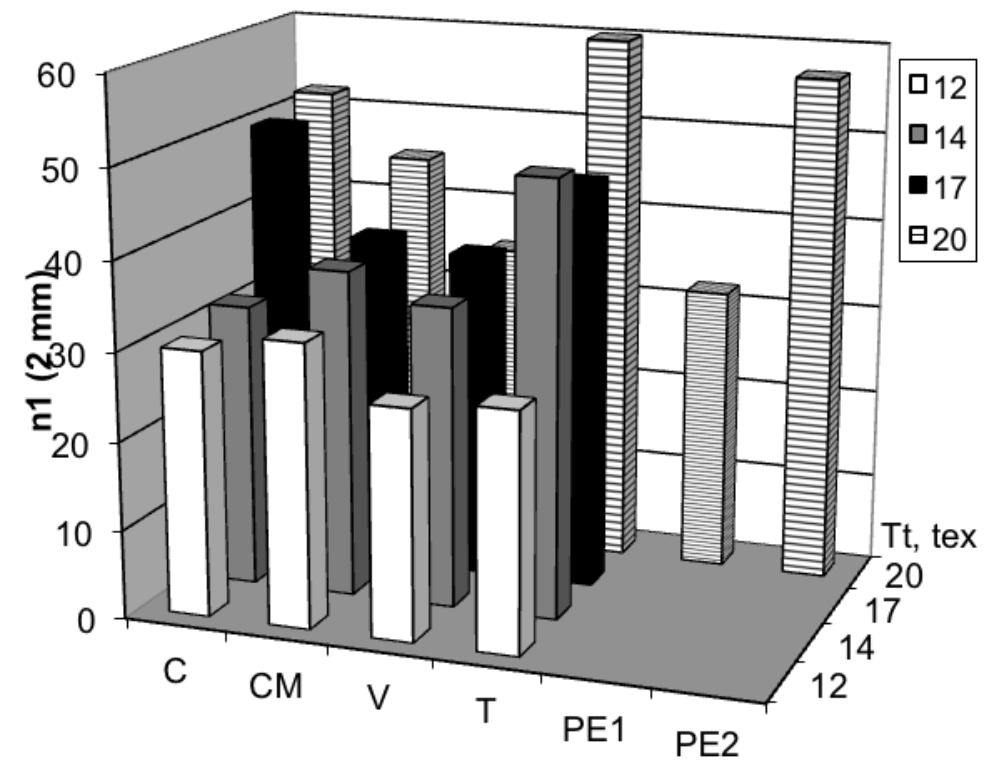

Fig. 8 Hairs in the length of $2 \mathrm{~mm}$

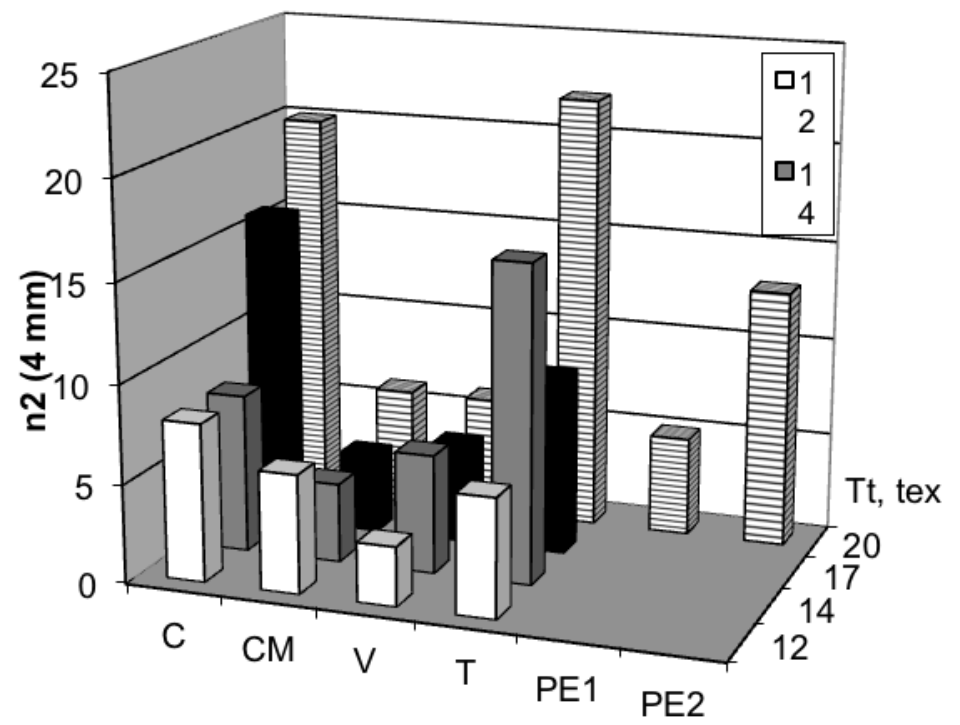

Fig. 9. Hairs in the length of $4 \mathrm{~mm}$

The results of yarn friction coefficient measurements are given on the Fig. 10.

The surface friction of yarn during knitting process needs to be at the lowest possible level to allow uniform running of yarn through machine elements. The reduction of 
friction directly affects the quality of produced goods. For further reduction of the friction coefficient, yarns need to be waxed during the production process.

The mean values of friction coefficient of all tested yarns are relatively low and range from 0.08 to 0.20 . By increasing the yarn fineness the yarn count, the friction coefficient increases for the majority of investigated yarns. Although the change is not so significant it may be concluded that the friction coefficient depends on the yarn fineness and type of fibers. It is well seen that the values are lower for yarns made of natural polymers (i.e. viscose and Tencel ${ }^{\circledR}$ ).

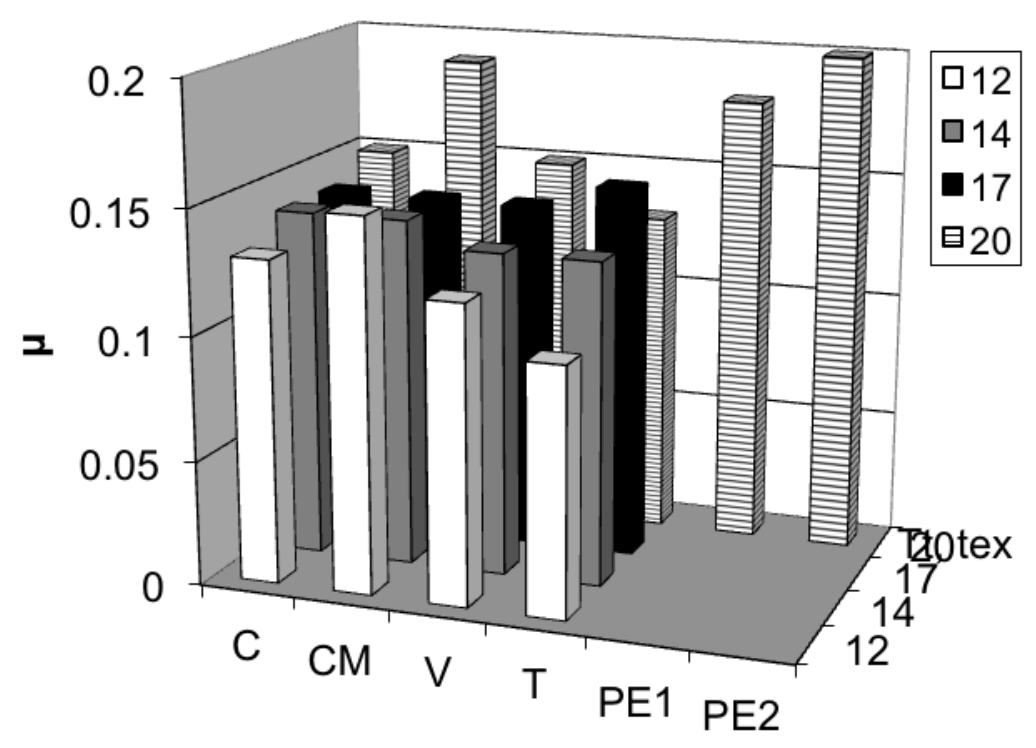

Fig. 10. Friction coefficient of investigated yarns

\section{Concluding remarks}

The study presented in this chapter is focused at the investigation of a comprehensive list of yarn properties that are influenced by different raw material or determined yarn count. Additional comparisons with the recommended values from the literature and the parameters of the yarn manufacturers have also indicated that the yarn parameters are within satisfactory limits.

Optimal performance of textile materials can only be achieved if all parameters of yarn design and production have been chosen meticulously in accordance with the requirements determined by the application of the product. The main remarks, outlined in this study, represent a meaningful contribution for designers and producers and should be used to design optimal yarn properties that will improve the performance of fabrics, as a final product. 
Salopek Cubric, I. \& Skenderi, Z.: Design of Yarn Properties for Improved Fabric ...

\section{Aknowledgement}

The authors are sincerely grateful to the spinning mills Predilnica Litija and Predionica Klanjec (group Linz-Textil) for their contribution in the production of yarns. The paper is published with the support of the University of Zagreb.

\section{References}

ASTM D3108 - 07 (2007). Standard Test Method for Coefficient of Friction, Yarn to Solid Material

Cai, Y.; Cui, X.; Rodgers, J.; Thibodeaux, D.; Martin, V.; Watson, M. \& Pang, S (2013). A comparative study of the effects of cotton fiber length parameters on modeling yarn properties. Textile Research Journal, 83, 9, 961-970, 0040-5175

Dayik, M. (2009). Prediction of Yarn Properties Using Evaluation Programing Textile Research Journal, 79, 11, 963-972, 0040-5175

ISO 2062:2009 Textiles -- Yarns from packages -- Determination of single-end breaking force and elongation at break using constant rate of extension (CRE) tester Iyer, C.; Mammel, B.; Schäch, W. (1992). Circular Knitting, Meisenbach GmbH,Bamberg, Germany

Lawrence C. A. (2003). Fundamentals of spun yarn technology, CRC Press, 1-56676821-7, Boca Raton, USA

Salopek Cubric, I.; Skenderi, Z.; Havenith, G. (2013). Impact of raw material, yarn and fabric parameters and finishing on water vapor resistance, Textile research journal, 83, 12, 1215-1228, 0040-5175

Salopek Cubric, I. \& Skenderi, Z. (2010). Approach to the prediction of thermophysiological comfort, Chapter IX in DAAAM International Scientific Book 2010, B. Katalinic (Ed.), 81-90, DAAAM International, 978-3-901509-74-2, ISSN1726-9687, Vienna, Austria

Salopek Cubric, I. (2009). Study of the thermophysiological comfort of knitted structures, Doctoral thesis, Zagreb, Croatia

Salopek I. \& Skenderi, Z. (2007). Water vapour resistance of knitted fabrics in the function of thermophysiological comfort, Proceedings of the 18th International DAAAM Symposium "Intelligent Manufacturing \& Automation: Focus on Creativity, Responsibility and Ethics of Engineers", Katalinic, B. (Ed.), 3-901509-58-5, Zadar, Croatia, 24-27th October, DAAAM International, Vienna

Ünal, P.; Özdil, N. \& Taskin, C. (2009). The Effect of Fiber Properties on the Characteristics of Spliced Yarns Part I: Prediction of Spliced Yarns Tensile Properties. Textile Research Journal, 80, 5, 429-438, 0040-5175

Ureyen, M. E. \& Kadoglu H. (2006). Regressional Estimation of Ring Cotton Yarn Properties from HVI Fiber Properties, Textile Research Journal, 76, 5, 360-366, 0040-5175

Uster Technologies AG (2007). Uster ${ }^{\circledR}$ Statistics, Uster Technologies AG, Uster, Switzerland 